\title{
Tonsillar Crypts and Bacterial Invasion of Tonsils: A Pilot Study
}

\author{
R.K. Mal ${ }^{*}$, , A.F. Oluwasanmi ${ }^{1}$ and J.R. Mitchard ${ }^{2}$ \\ ${ }^{1}$ University Department of Otolaryngology, Southmead Hospital, Bristol, UK \\ ${ }^{2}$ Department of Pathology, Southmead Hospital, Bristol, UK
}

\begin{abstract}
Objective: To investigate histologically if a lack of protection of the deep lymphoid tissue in tonsillar crypts by an intact epithelial covering is an aetiological factor for tonsillitis.

Method: A prospective histological study of the tonsillar crypt epithelium by immunostaining for cytokeratin in 34 consecutive patients undergoing tonsillectomy either for tonsillitis or tonsillar hypertrophy without infection (17 patients in each group).

Results: Discontinuity in the epithelium was found in $70.6 \%$ of the groups of patients with tonsillitis and in $35.3 \%$ of the groups of patients with tonsillar hypertrophy. This is of borderline significance.

Conclusion: We found no clear correlation between tonsillitis and a defect in the tonsillar crypt epithelium. Tonsillitis might be due to immunological differences of subjects rather than a lack of integrity of the crypt epithelium. Further study with larger sample size and normal control is suggested.
\end{abstract}

Keywords: Tonsillitis. tonsillar hypertrophy, tonsillar crypt epithelium.

\section{INTRODUCTION}

The association of lymphoid tissue with protective epithelium is widespread, eg skin, upper aerodigestive tract, gut, bronchi, urinary tract.

The function of the palatine tonsils, an example of an organised mucosa-associated lymphoid tissue, is to sample the environmental antigen and participate with the initiation and maintenance of the local and systemic immunity.

The epithelium lining the tonsillar crypts is a stratified squamous epithelium with patches of reticulated epithelium which is much thinner, with a discontinuous basal lamina, but has an unbroken oropharyngeal surface. The epithelium is exceedingly thin in places so that only a tenuous cytoplasmic layer separates the pharyngeal lumen from the underlying lymphocytes.

Epithelial cells are held together by small desmosomes anchored into bundles of keratin filaments. Interdigitating dendritic cells are also present. The intimate association of epithelial cells and lymphocytes facilitates the direct transport of antigen from external environment to the tonsillar lymphoid cells [1].

The palatine tonsils themselves are frequently prone to infection as indicated by the frequency of tonsillectomy.

Streptococcus is the commonest bacteria causing tonsillitis. Hokonohara et al. [2] in an animal experiment demonstrated the susceptibility of tonsils to infection on

*Address correspondence to this author at the University Department of Otolaryngology, Southmead, Hospital, Westbury on Trym, Bristol, BS10 5 NB, UK; Tel: 01179 595158; Fax: 01179 595850;

E-mail:malr@doctors.org.uk exposure to Group A streptococci, the pharynx, larynx, trachea, bronchi and lungs being resistant. The infection apparently occurrs through the micropore of the crypt epithelium.

A. Jacobi in his presidential address in 1906: "The tonsil as a portal of microbic and toxic invasion" stated: "A surface lesion must always be supposed to exist when a living germ or toxin is to find access. Stoher has shown small gaps between the normal epithelia of the surface of the tonsil". He also quoted George B. Wood : "It has been proven by several very thorough and capable investigators that foreign bodies in the crypts can pass through the epithelium into the inter follicular tissue" [3].

A.J. Wright observed in 1950: " The epithelium of these crypts is frequently absent in parts, thus bringing the lymphoid tissue into direct contact with the surface [4].

A breach in the continuity of the epithelium could explain the susceptibility of the tonsils to infection and we carried out a pilot study to investigate the integrity of the crypt epithelium by using immunostaining for cytokeratin.

\section{MATERIAL \& METHOD}

Ethical approval was obtained from the hospital ethical committee and ethical standards were followed.

Thirty-four consecutive patients who were admitted for tonsillectomy by author, A.O. were recruited. No one refused to participate in the study. The indication for tonsillectomy was repeated tonsillitis in one group and large tonsils causing obstructive sleep apnoea without any history of tonsillitis in another group.

There were at least twelve episodes of tonsillitis prior to the operation. A period of at least six weeks was allowed to 
pass after an attack of acute tonsillitis before the operation was performed.

The tonsils were removed by sharp / blunt dissection with minimal possible trauma to the tonsillar tissue. The two sides were dealt with separately, but in an identical manner. They were marked "side one" and "side two".

\section{Laboratory Methods (Including the Method Used for Producing the Immunohistochemically Stained Sections)}

The tonsillar tissue was fixed in $10 \%$ buffered formalin. Representative slices from each tonsil were embedded into paraffin wax and $4 \mu$ sections stained with haematoxylin and eosin. One section with the best array of crypts from each tonsil was chosen and was pretreated with $0.1 \%$ solution of Trypsin in 5\% calcium chloride solution for 10 minutes at 37 c for antigen retrieval and thereafter was treated with DAKO monoclonal Mouse Anti-Human Cytokeratin antibody, Clone MNF 116. The later reacts with cytokeratins 5,6,8,17 and probably also 19 , it shows an especially broad pattern of reactivity with human epithelial tissue from simple glandular to stratified squamous epithelium (www.dako.co.uk).

The sections were examined by light microscopy and apparent discontinuities in the crypt epithelium were sought and recorded as being present or absent. All the crypt epithelium in each slide was systematically examined. Foci of artefactual discontinuity were not included (Fig. 1b). Apparent epithelial discontinuity was regarded as being present if an imaginary line could be traced from the crypt lumen to the underlying lymphoid tissue without crossing visible epithelium (Fig. 1c, d). The microscopic examination was carried out without knowledge of the patient's identity or medical history. Any ulceration of the tonsillar surface was noted. The examination was done by a single observer (JRM).

\section{RESULTS}

There were 17 patients (M13, F4) in the tonsillitis group and 17 patients (M5, F12) in the non-infective (hypertrophy) group. The age of the infective group ranged from 4 to 32 , mean 14.9 years of age and the non-infective group ranged from 2 to 55, mean 10.7 years of age. None of the 68 tonsils had ulcers histologically. Of the total 68 tonsils examined, there were multiple areas of epithelial discontinuity in 21 $(30.9 \%)$. The distribution of the epithelial discontinuity is shown in Tables $\mathbf{1}$ and $\mathbf{2}$.

\section{Table 1. Diagnosis vs Discontinuity}

\begin{tabular}{|c|c|c|c|}
\hline & Infection & OSA & Total \\
\hline \hline No discontinuities & $5(31.3 \%)$ & $11(68.8 \%)$ & 16 \\
\hline $\begin{array}{c}\text { One or more discontinuities } \\
\text { (Unilateral or bilateral) }\end{array}$ & $12(66.7 \%)$ & $6(33.3 \%)$ & 18 \\
\hline Total & 17 & 17 & 34 \\
\hline
\end{tabular}

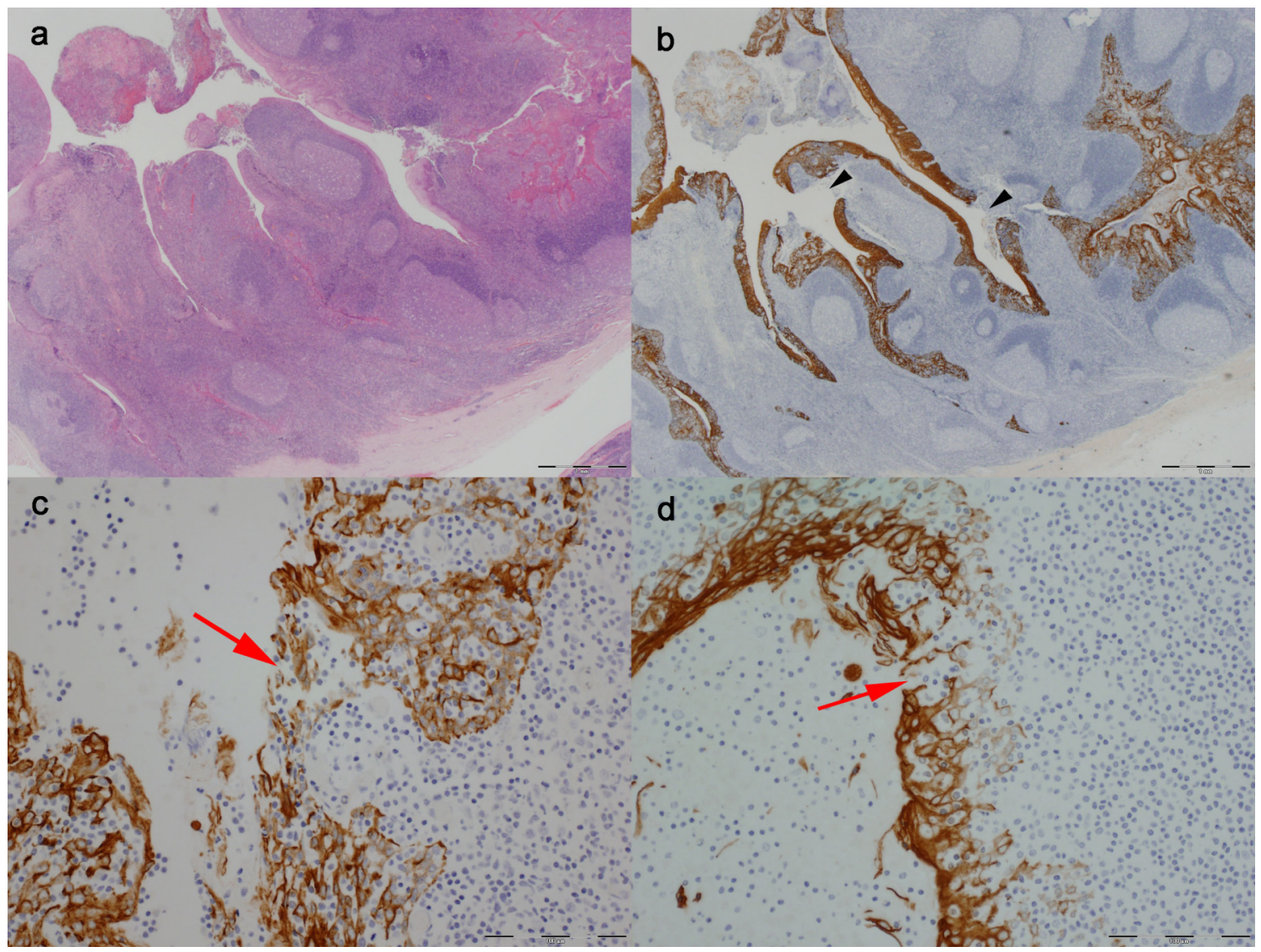

Fig. (1). Photomicrographs of tonsillar tissue. Low power $\mathrm{H}$ and $\mathrm{E}$ stained section of unremarkable tonsil, original magnification $\mathrm{x} 12.5$ (a). AE1/3 immunostained section of same area showing artefactual discontinuity of squamous epithelium (arrowheads), original magnification $\mathrm{x}$ 12.5 (b). High-power view of apparent epithelial discontinuities (arrows), AE1/3 immunostain, original magnification x 200 (c and d). 
Table 2. Diagnosis $v s$ Number of Discontinuities

\begin{tabular}{|c|c|c|c|}
\hline & Infection & OSA & Total \\
\hline \hline No discontinuities & $5(31.3 \%)$ & $11(68.8 \%)$ & 16 \\
\hline One discontinuity & $9(60.0 \%)$ & $6(40.0 \%)$ & 15 \\
\hline Two discontinuities & $3(100.0 \%)$ & $0(0.0 \%)$ & 3 \\
\hline Total & 17 & 17 & 34 \\
\hline
\end{tabular}

P (Fisher's exact test $)=0.06$.

$\mathrm{P}($ Cuzik test for trend $)=0.02$.

The finding of Table 1 suggest that there is more infection in those with discontinuities of the crypt epithelium but it is only of borderline significance.

The data in Table $\mathbf{2}$ is limited as only three cases had bilateral discontinuities and all had infection.

The statistical analysis was carried out by statistician Elise Whitley, Department of Statistics, North Bristol NHS Trust.

\section{DISCUSSION}

The recurrent nature of acute tonsillitis has been attributed to the bacteria surviving intracellularly, thus avoiding antibiotic exposure and subsequently escaping the cellular confine to cause reinfection [5].

The presence of a bacterial bio film in the tonsillar crypts might explain the chronicity and recurrent nature of some form of tonsillitis. The bacteria in the bio film would be out of reach of antibiotics [6].

Anders Ebenfelt and colleagues in their careful study came to the conclusion that the inflammatory process takes place outside the surface of the epithelial cells. It takes place in the secretion with hardly any direct contact between the bacteria and the epithelial surface and no penetration of bacteria in the cells. This is contrary to conventional wisdom and also would not explain how tonsillitis is associated with peritonsillar abscess [7,8].

It has been reported that the bacteriological profile of tonsillar core swab culture and fine needle aspirate culture is very similar in groups of patients with tonsillitis [9]. Several authors have reported that there is a high bacterial load in tonsils in groups of patients with tonsillitis compared to control groups without tonsillar pathology [9-11]. The bacterial load is equally high in groups of patients with tonsillar hypertrophy without tonsillitis compared to control subjects without any tonsillar pathology [10, 11]. Both tonsillitis and tonsillar hypertrophy are associated with marked elevation of immunologically active cell population in the tonsils compared to the control [11]. It appears that high bacterial profile in the tonsils in some subjects causes tonsillitis and in others it leads to tonsillar hypertrophy without clinical symptoms of tonsillitis. Immunological studies are often based on tonsillar tissue [12-17] and it would be tempting to conclude that tonsils have a special immunological function inducing researchers to choose tonsils, but the easy accessibility of tonsillar tissue might be the other explanation or at least a partial one. The tonsils may however have some special immunological function, e.g., polymeric IgA1 deposited in glomerular mesandium in IgA nephropathy is at least in part of tonsillar origin [18]. There is an inverse relationship between tonsillitis and asthma [19]. Scrutiny of subpopulation of IgG secreting cells from tonsils and bone marrow showed CD38 low IgG secreting cells were present exclusively in tonsils [20]. The concentrations of disease- related prion protein in variant Creutzfeldt-Jakob disease are not uniform throughout the lymphoreticular system but are consistently higher in tonsils [21].

An abstract of our finding has been published elsewhere [22]. Reichel et al. in their study comparing the histology of tonsils of patients with recurrent tonsillitis to tonsils of patients with tonsillar hypertrophy found similar degree of hyperplesia and the same degree of fresh but mild inflammation within the crypts. Chronic inflammation of the tonsillar tissue was present in both groups but more common in the tonsillitis group. Fibrosis was uncommon (9\%) and occurred only in the tonsillitis group [23].

As mentioned earlier there has been a historical concept that there are actual gaps in the epithelial covering in the tonsillar crypts allowing entry of pathogens to the tonsillar parenchyma [4] and we have tried to examine the validity of this concept in our study.

We have demonstrated by cytokeratin immunostaining that an apparent breach in the crypt epithelium occured in $30.9 \%$ of the tonsils examined. The epithelial breach is commoner in the tonsillitis group of patients $(70.6 \%)$ than the tonsillar hypertrophy group of patients $(35.3 \%)$ but the difference is only of borderline significance. It is thus not possible to conclude that the susceptibility of tonsils to infection is due to a breach in the epithelial lining.

The evidence from our observation and findings of the recent observers mentioned above might indicate that susceptibility to tonsillitis is determined by an immunological difference of the subjects rather than a mechanical failure in the tonsillar structure.

The weakness in our study is a lack of normal control without any tonsillar pathology. It is not easy to recruit normal control for obvious reasons. The relatively small sample size of this pilot study (although large enough for analysis) is another weakness. Confocal study might have demonstrated the epithelial breach more clearly.

\section{CONCLUSION}

Tonsils are very prone to infection despite their presumed protective function. A breach in the tonsillar crypt epithelium has been reported before. We examined the crypt epithelium by cytokeratin immunostaining in a tonsillitis group and a tonsillar hypertrophy group of patients.

There was a breach in the crypt epithelium in a proportion of cases in both groups but the difference was only of a borderline significance.

The evidence from our observation and the work of the recent observers namely an increased bacterial load of the tonsils in some subject cause tonsillitis and tonsillar hypertrophy in others and also that tonsils have special immunological function indicate that susceptibility to tonsillitis might be determined by an immunological 
difference of the subjects rather than a mechanical failure in the tonsillar structure.

A further study with larger number of patients including normal control (ethics permitting) including confocal studies would be worthwhile to confirm the findings of our pilot study.

\section{ACKNOWLEDGEMENTS}

We thank Dr. K. Denton for her advice, Mrs. Eva Hicks for administrative help and Mrs. Karin Sibley for technical assistance.

\section{REFERENCES}

[1] Standring S, Ed. Grays Anatomy. 39th ed. Livingstone, Elsevier Churchill 2005; p. 625.

[2] Hokonohara M, Yoshinaga M, Inoue H, Haraguchi T, Miyata K. Experimental studies on the initial focus of invasion of group A streptococci. Acta Otolaryngol 1998; Suppl. 454: 192-96.

[3] Jacobi A. The tonsil as a portal of microbic and toxic invasion. Arch Pediatr 1950, 67(11): 531-39.

[4] Wright AJ. Tonsillar function---review of the evidence. J Laryngol Otol 1950; 64 (1): 1-11.

[5] 'O'sterlund A, Popa R, Nikkila T, Scheynius A, Engstrand L. Intracellular Reservoir of Streptococcus pyogenes In Vivo: A possible explanation for recurrent pharyngotonsillitis. Laryngoscope 1997; 107: 640-47.

[6] Chole RA, Faddis BT: Anatomical evidence of microbial biofilms in tonsillar tissue: a possible mechanism to explain chronicity. Arch Otolaryngol-Head Neck Surg 2003; 129(6): 634-36

[7] Ebenfelt A, Ericson LE, Lundberg C. Acute pharyngotonsillitis is an infection restricted to the crypt and surface secretion. Acta Otolaryngol (Stockh) 1998; 118: 264-71.

[8] Ebenfelt A: Bacterial adherence to mucosal epithelium in the upper airway has less significance than believed. Negat Results BioMed 2003; 2 : 3 doi: 10.1186/1477-5751-2-3

[9] Gaffney RJ, Cafferkey MT. Bacteriology of normal and diseased tonsils assessed by fine-needle aspiration: Haemophilus influenzae and the pathogenesis of recurrent acute tonsillitis. Clin Otolaryngol 1998; 23: 181-85

[10] Stjernquist-Desatnik A, Prellner K, Schale'n C. High recovery of Haemophilus influenzae and group A streptococci in recurrent tonsillar infection or hypertrophy as compared with normal tonsils. J Laryngol Otol 1991; 105: 439-41.
[11] Brodsky L, Moore L, Stanievich J. The role of Haemophilus influenzae in the pathogenesis of tonsillar hypertrophy in children. Laryngoscope 1988; 98: 1055-60.

[12] Hajoui O, Janani R, Tulic M, et al: Synthesis of IL-13 by human B lymphocytes: Regulation and role in IgE production. J Allergy Clin Immunol 2004; 114(3): 657-63.

[13] Page M, Lebecque S, Miossec P. Anatomic localization of dendretic cells subsets and plasmacytoid-like Th1 T lymphocytes in rheumatoid synovium: correlation with selective chemokine expression. Arthritis Res 2002; 4(Suppl 1): 55 doi: 10.1186/ar498.

[14] Renaudineau Y, Haget N, Youinou P. Two promoters for the CD5 gene: one operating in $\mathrm{T}$ cells and activated $\mathrm{B}$ cells and another restricted to resting B cells. Arthritis Res 2002; 4(Suppl 1): 25 doi: $10.1186 /$ ar465

[15] Vidal-Rubio B, Sanchez-Carril M, Oliver-Morales J, GonzalezFemandez A, Gambon-Deza F: Changes in human lymphocyte subpopulations in tonsils and regional lymph nodes of human head and neck squamous carcinoma compared to control lymph nodes. BMC Immunol 2001; 2: 2 .

[16] Teague RM, Harlan LM, Benedict SH, Chan MA: MIP-1(alpha) induces differential MAP kinase activation and I (kappa)B gene expression in human B lymphocytes. J Interferon Cytokine Res 2004; 24 (7): 403-10.

[17] Shen Y, Iqbal J, Xiao L, et al. Distinct gene expression profiles in different B-cell compartments in human peripheral lymphoid organs. BMC Immunol 2004; 5: 20 doi: 10.1186/1471-2172-5-20

[18] Xie Y, Chen X, Nishi S, Narita I, Gejyo F. Relationship between tonsils and IgA nephropathy as well as indications of tonsillectomy Kidney Int 2004; 65(4): 1135-44.

[19] Ceran O, Aka S, Oztemel D, Uyanik B, Ozkozaci T. The relationship of tonsillar hyperplesia and asthma in a group of asthmatic children. Int-J-Pediatr-Otorhinilaryngol 2004; 68(6): 775-78.

[20] Arce S, Luger E, Muehlinghaus G, et al. CD38 low IgG-secreting cells are precursors of various CD38 high-expressing plasma cell populations. J Leukoc Biol 2004; 75(6): 1022-28.

[21] Wadsworth JDF, Joiner S, Hill AF, et al. Tissue distribution of protease resistant prion protein in variant Creutzfeldt-Jakob disease using a highly sensitive immunoblotting assay. Lancet 2001; 358: 171-80.

[22] Mal RK, Oluwasanmi AF, Mitchard JR. Tonsillar crypts and bacterial invasion of tonsils. Clin Otolaryngol. 2008; 33(3): 293-5.

[23] Reichel O, Mayr D, Winterhoff J, de la Chaux R, Hadehorn H, Berghaus A. Tonsillotomy or tonsillectomy? - a prospective study comparing histological and immunological findings in recurrent tonsillitis and tonsillar hyperplesia. Eur Arch Otolaryngol 2007; 264(3): 277-84. 